\title{
The Intricacies Involved in the Analysis and Interpretation of Hammer Transfer Stain/s in a Crime Scene
}

\author{
Samir Kumar Bandyopadhyay and Nabanita Basu
}

Department of Computer Science and Engineering, University of Calcutta, India

\begin{abstract}
Bloodstain Pattern analysis particularly deals with the reconstruction of dynamic bloodletting events from static bloodstain patterns. Bloodstain patterns often help to sequence events that might have occurred at a crime scene. It can also be used to draw inference about the position of the victim/s, perpetrator/s and bystander/s (if any) at the crime scene. This paper is aimed at intricate analysis/interpretation of transfer stains produced by blunt ended objects at a crime scene. By way of experiments performed within a laboratory setting this paper attempts at establishing that hammer transfer stain or possible weapon transfer stain at a crime scene does not indicate that that particular instrument has been used to murder the victim/s. Also when blood drips over hammer and when a hammer falls under gravity onto a blood pool, the stain patterns formed are particularly different. This particular information under certain circumstances could particularly contribute to sequencing of events at a crime scene. Again, different blunt ended objects were found to produce similar transfer stain patterns. Hence transfer stain patterns should be interpreted in coherence with other relevant circumstantial evidence at the crime scene.
\end{abstract}

Keywords: Blunt force trauma, Bloodstain Pattern Analysis, Hammer, Transfer Stain, Head hit, crime scene.

\section{INTRODUCTION}

In 2011, Federal Bureau of Investigation (FBI) reported that the number of individuals killed (496) by blunt objects which might include a hammer, golf stick, a coconut shell (ripe, unripe), a wooden box, a candlestick etc. by far outnumbered the number of individuals killed by rifle shot (Washington CBS Local, 2013). It's not just 2011 recorded such figures, since 2005 to 2011, the number of individuals who have been killed by a blunt object hit have by far outnumbered the number of individuals killed by a rifle shot (Wahington CBS Local, 2013). The bloodstain resulting from contact between a blood bearing surface and another surface' is defined as Transfer stains by the International Association of Bloodstain Pattern Analysts (IABPA) (SWGSTAIN, 2009). Identification of a murder weapon can be done by analyzing weapon transfer stains (if any) together with other circumstantial evidence at a crime scene. Hand transfer stains, shoe transfer stains as also weapon transfer stains left at a crime scene play an integral role in the reconstruction of the crime scene, hence proper documentation of such stains is mandatory.

In this regard, the case of the ex-FBI agent in 2010 is particularly relevant. On December 13, the Sun News reported how the imprint of hammer in the blood pool could influence the court's understanding of the case as a case of successful attempted murder or a murder committed in self defense (Toplikar, 2010). It is

*Address correspondence to this author at the Department of Computer Science and Engineering, University of Calcutta, India;

E-mail: skb1@vsnl.com the proceedings of the aforementioned case that make the study of hammer imprints in blood pool together with weapon transfer stains particularly relevant and indeed timely. As rightly put forward by the defense attorney, Thomas Pitaro, the claimed hammer imprint theory with reference to the hammer imprint lying close to the hand of the victim was not recorded in the police report and was only added much later under the able guidance of a certified bloodstain pattern analyst Daniel Holstein (Toplikar, 2010).

The authors of this work comprehend that the imprint went unnoticed largely due to the police officials being unaware of the different sorts of hammer or blunt object transfer stains or imprints that could particularly influence the sequencing of events in a crime scene.

This paper aims at documenting possible domain knowledge that could help crime scene investigators identify or sequence events based on hammer imprints /hammer like imprints in a blood pool or blunt object transfer stains together with other circumstantial evidence. The hypotheses that the authors intend to test in this work can be summarized as follows

The presence of a hammer or hammer-like imprint in a blood pool does not necessarily imply that that the particular tool has been used as the murder weapon in the particular crime scene

Bloodstain imprints formed when a hammer is placed in a blood pool and then placed on a different surface and when a sufficient quantity of blood drips or falls under gravity from a height of 
$10 \mathrm{cms}$ (say) over a hammer lying on a plain, non-absorbent surface are particularly different.

Stains resembling hammer imprints could be created with other blunt ended objects as well.

The paper has 7 basic sections. While Section 1 (Introduction) introduces the topic, Section 2 (Literature Review) briefly describes work that had been previously conducted in terms of weapon transfer stains and blood-pool imprint patterns. Section 3 (Hypotheses Generated) highlights the hypothesis formed and thereby studied by experimentation. Section 4 (Methodology Adopted) describes the methodology that had been adopted to prove or disprove the hypothesis in question. Section 5 (Results) summarizes the findings of the study. While section 6 (Discussion) presents a way the understanding of these stain patterns and how they can be used/studied in conjunction with other circumstantial evidence in a crime scene. Section 7 presents ways in which this particular work could be extended in the near future.

\section{LITERATURE REVIEW}

In Forensic Science evidences can particularly be classified under two heads- Associative Evidence and Reconstructive evidence. Bloodstain patterns obtained at/from a crime scene are used in sequencing of events in a crime scene (Bevel \& Gardener, 2002). In particular, Professor MacDonell's contribution to the research and interpretation of bloodstain pattern analysis since 1971 stands commendable till date (James, 1998). The Association of Crime Scene Reconstruction defines reconstruction as "the use of scientific methods, physical evidence, deductive and inductive reasoning and their inter-relationships to gain explicit knowledge of the series of events that surround the commission of a crime." (Bevel \& Gardener, 2002) T. Bevel and M. Gardener in their book on "Blood Stain Pattern Analysis $3^{\text {rd }}$ edition- An Introduction to Crime Scene Reconstruction' have explicitly explained the different types of bloodstain patterns as described by the International Association of Bloodstain Pattern Analysts (Bevel \& Gardener, 2002). The book also contains a detailed classification of bloodstain patterns. How patterns vary with difference in angle of impact, fall height, temperature, surface texture, surface absorption capability etc. has been neatly documented in the book (Bevel \& Gardener, 2002). Crime scene documentation and reconstruction using bloodstain patterns in particular forms the highlight of the book.
However, the classification system put forward in the book is somewhat debatable within the community of the bloodstain pattern analysts. For example, the book describes Expectorate stain pattern to be formed when blood is forcefully ejected from the throat, nose or respiratory system under pressure. This sort of stain, as the book states may contain air vacuoles, mucous strands, epithelial cells etc (Bevel \& Gardener, 2002). However, high impact stains might also contain air vacuoles or ringlets, though they are not Expectorate spatter/Expiration stains. The bloodstain classification system put forward by James et al., 2005 stands much more acceptable in the analysis of real world crime scenes (Brodbeck, 2008). Dr. Brodbeck's article on 'Introduction to bloodstain pattern analysis', provides important factors when documenting the bloodstain patterns at a crime scene (Brodbeck, 2008). James, Sutton and Kish's book on 'Principles of Bloodstain Pattern Analysis: Theory and Practice' also explicitly explains the use of bloodstain evidence and its effective use with other circumstantial evidence for sequencing the events in a particular crime scene (James, Kish \& Sutton, 2005). Stuart H. James's book on 'Scientific and Legal Applications of Bloodstain Pattern Interpretation' outlines the rules for documentation and presentation of bloodstain patterns within a juridical setting. Illes et al. presented a set of criteria for selection of patterns in an impact spatter using a statistical model (Illes \& Boue, 2011). Proper selection of stains in an impact spatter is particularly important for calculation of the area of origin of the impact that created the particular spatter stain. Shen, Brostow, Cipolla developed an algorithm for automated estimation of a body's 2D location on a floor plan when the body is impacted given that the blood stains are formed as a result of impact spatter (Shane, Brostow \& Cipolla, n.d.).

This study is particularly inspired from the work of Barksdale, Sims and Vo in which they compared a reference array of knife impressions with impressions obtained from two real life crime scenes (Barksdale, Sims \& Vo, 2004). The main highlights of the study were that the knife impressions stains may display enough characteristics for an individual to match it to a suspected knife. Also the weight of a knife is highly unlikely to be sufficient to produce a void pattern in a blood soaked surface by way of reverse capillary action (Barksdale, Sims \& Vo, 2004). John J. Nordby documented the scientific basis/explanation that governs the mechanism of bloodstain pattern/spatter formation in a crime scene (Nordby, 2006). 
Murderpedia.com provided the authors with a database of criminal cases in which the victim was killed by hammer hit (Blanco, n.d.). Press publications, court proceeding for each of the recorded crime cases at Murderpedia.com helped the authors conceptualize this particular piece of work (Blanco, n.d.).

\section{HYPOTHESIS GENERATED}

The study undertaken aims at approving or disapproving the hypotheses drawn up by way of experimentation based on close and careful observation. The hypotheses were drawn up from certain experimentation undertaken by the authors in a closed laboratory environment together with their basic understanding of case proceedings from different criminal cases (Blanco, n.d.).

Hypothesis 1: If the transfer stain or imprint of a hammer or hammer like blunt object is present at the crime scene it does not necessarily imply that the particular tool has been used as a murder weapon in the crime scene.

Hypothesis 2: Based on the quantity of blood, hammer shape and material, the transfer stain formed when a hammer is placed in a blood pool and then placed on a plain non-absorbent surface shall be markedly different from the transfer stain formed when blood is allowed to drip over a hammer and then an impression of its face is taken.

Hypothesis 3: Stains resembling hammer or hammer-like transfer stains /imprints could also be created with other blunt ended objects. So circumstantial evidence needs to be taken under consideration when squaring up on a particular type of murder weapon.

\section{METHODOLOGY ADOPTED}

The Methodology section can further be subdivided into the following subsections - Blood procurement, Experiments performed, Pitfalls/Noise if any and how was it handled in the course of the experiments.

\subsection{Blood Procurement}

Porcine or Bovine blood are quite similar to human blood (Amin \& Sirs, 1985). So in order to study real life crime scene stains porcine blood was used to simulate real life hammer/blunt object head hit events. Fresh pig blood was legally procured from the Municipal pig slaughter house located at Tangra, Kolkata. As fresh blood coagulates over time, 1100 IU of Heparin injection was thoroughly mixed with $500 \mathrm{ml}$ of fresh pig blood to prevent coagulation.

\subsection{Experiments}

With respect to the hypothesis generated, 6 different yet commonly available hammers were procured. Table 1 provides the front, side and isometric view of the 6 hammers used in the study.

White, plain paper (A3 size) was used for recording the bloodstains formed on a plain, non-absorbent surface. Paper was used because it approximately mimics the type of bloodstain we can expect to see on a plain, non-absorbent surface (such as tiled floor, marbled floor, wall paper, wood surface etc.). However, the drying time for a stain, formation of dent due to abrupt fall of a hammer of varied weights, sizes may slightly vary depending on the surface texture, hardness of the material/surface in comparison to the hammer head. For example, while abrupt fall of hammer on paper (say from a height of $40 \mathrm{cms}$ ) after 10 head hits might leave a rough impression of the head of the hammer on paper, in case of a tiled floor the same hammer used under similar conditions might just leave a small dent.

The temperature and humidity of the room was accordingly recorded on the day the experiment was conducted. In the first instance, a $30 \mathrm{cc}$ blood pool with outlines as demonstrated in Figure 1 was created. Hammers one by one were placed in the blood pool for a brief period of 10 minutes (measure with a stop watch) and the hammer was then placed with the bloody face down on a plain, non-absorbent $A 3$ size paper.

In the second stage of the experiment, the 6 hammers were made to lie on different sheets of paper, and $20 \mathrm{cc}$. of blood was poured on each of the 6 different hammers respectively. The hammers were made to lie for a period of 20 minutes and the impressions of the face down side of the hammers were recorded on other sheets of papers, how the blood had trickled below the hammer to form a pool was also recorded for each of the 6 hammers.

Lastly, six pools of $20 \mathrm{cc}$. blood were created on a mount-board (a mount board has greater absorption ability compared to a plain, non absorbent, printer paper). Mount board was used to record the imprint in blood as because paper was found unable to sustain or 
Table 1: A tabular representation of the front view, side view and isometric view of each of the 6 hammers [Figures marked with HF represent the front view of the respective hammer, Figures marked with HS represent the side view of the respective hammer, when the two edges of the hammer have different dimensions, two side view images have been documented, Figures marked with HI represent the Isometric view of each other hammers]

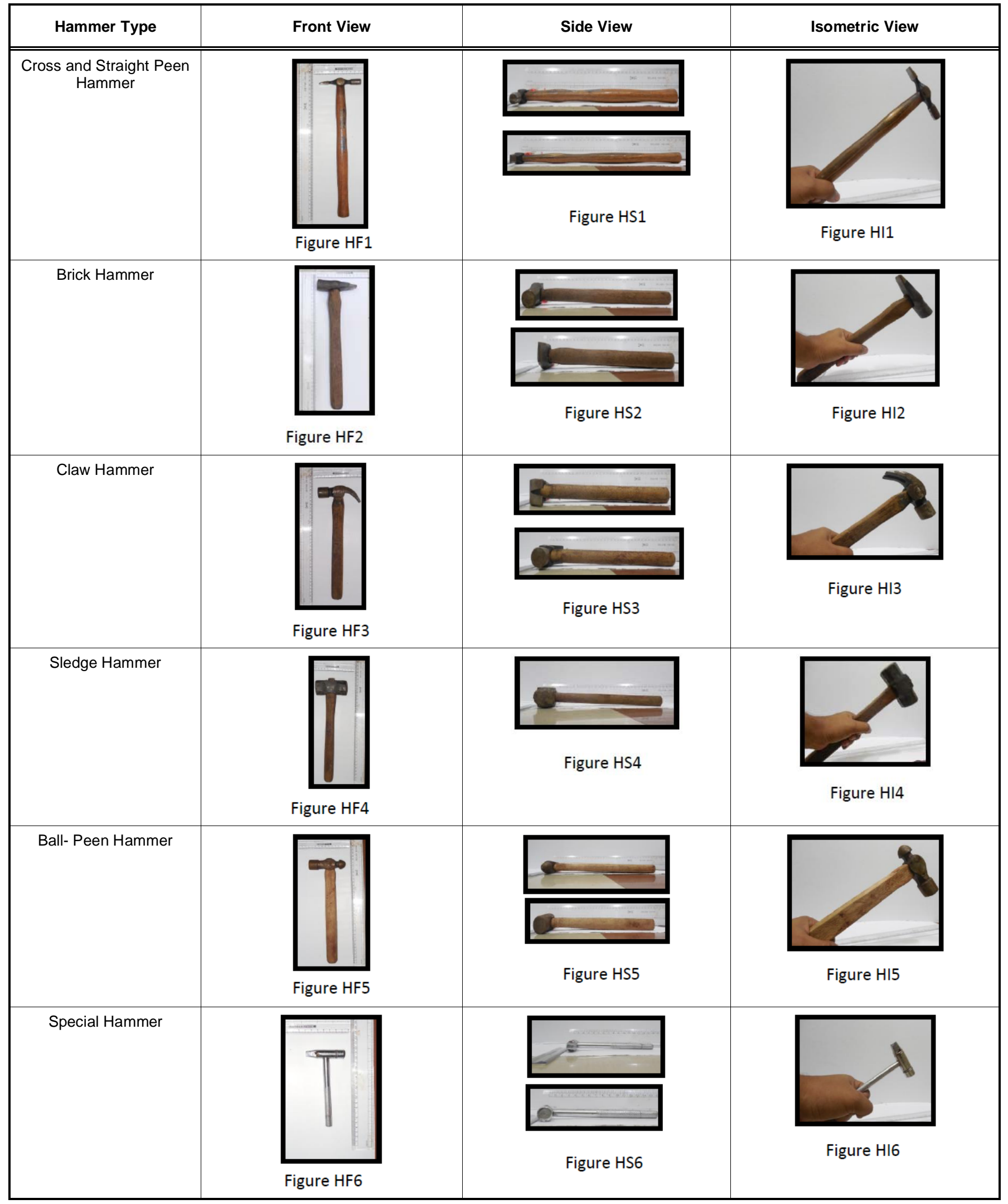




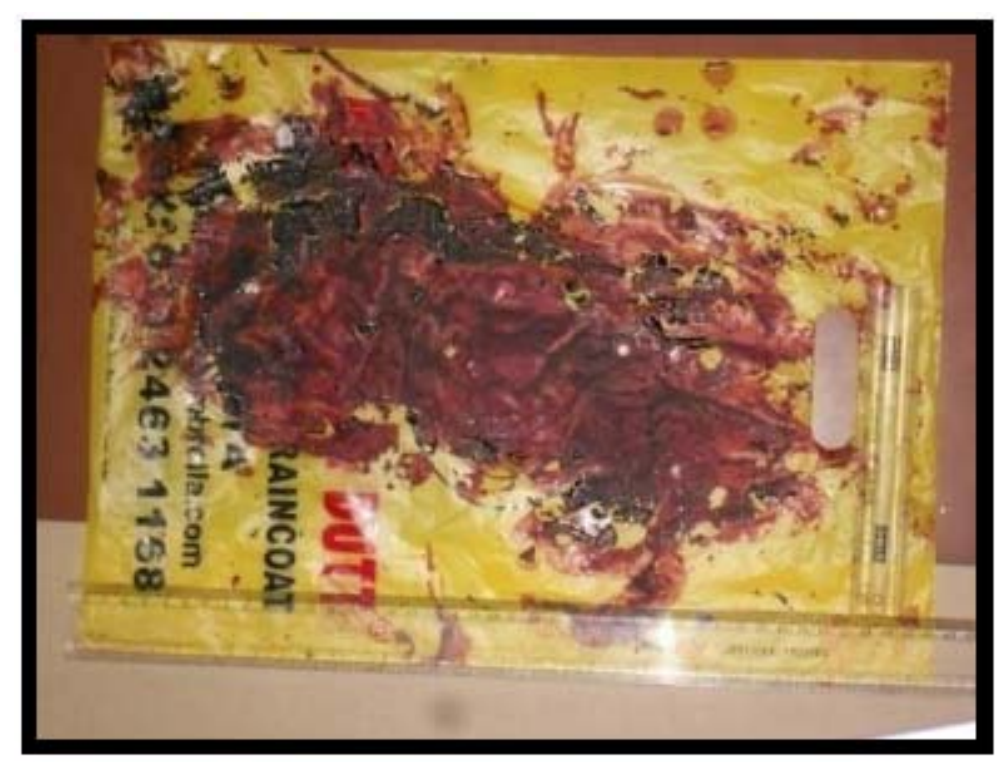

Figure 1: Blood pool created with $30 \mathrm{cc}$. blood on a plastic bag. The pool was created on a plastic bag as because unlike plain paper after drying the plastic bag surface does not cringe.

record the stain when attempts were made to record the same stains on plain paper alone. So a mountboard with a plain non-absorbent paper attached to one of its sides was used to record the stains. The 6 different hammers were placed faced down on each of the 6 different pools respectively. The pools were allowed to dry with the hammer lying in the blood pool face down.

An empty coconut with artificial hair wig was used to stimulate the event of a head hit (refer Figure 2).

\subsection{Pitfalls}

The pitfalls of the experimental design can be outlined as follows:
1. When it comes to simulation of head hit, the authors are not certain of the level of accuracy of the head hit simulation. The authors tried to achieve the best possible ethical simulation that was possible.

2. There are many more hammers (Diydata, n.d.) that could cause fatal head injury to humans and animals when used as a murder weapon, however it wasn't possible to avail all those hammers at the local market but by way of case study the authors have picked out the most commonly available hammers, and tried to prove / disprove our hypothesis based on these common hammers (Blanco, n.d.).

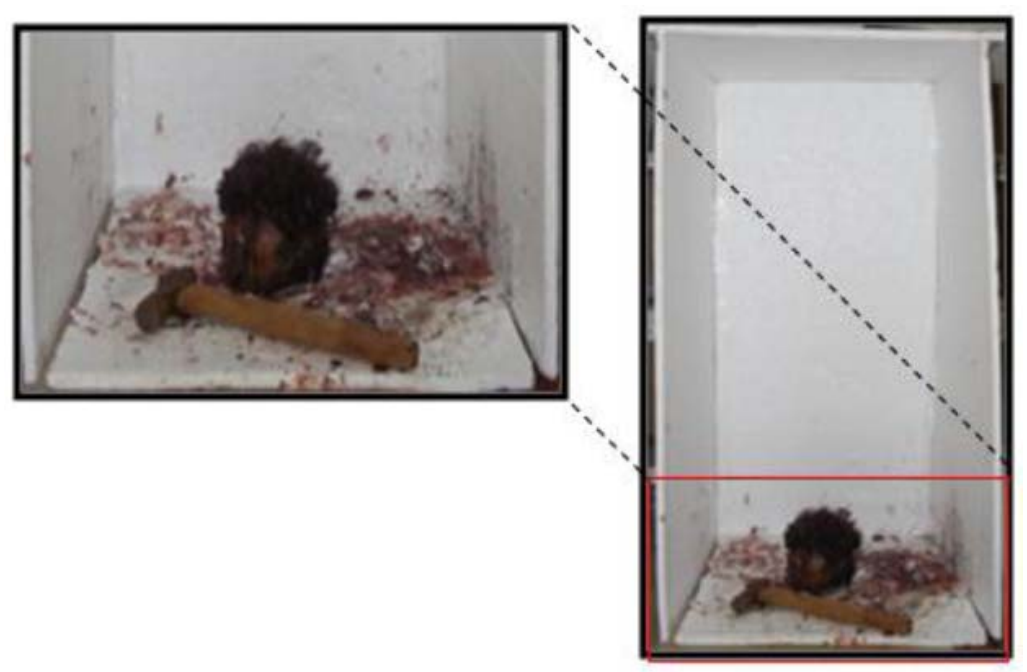

Figure 2: Head Hit simulation done using a hollow coconut shell and hair wig. 
Table 2: Images of Different Transfer stains (Column 1 and Column2) when the hammer had fallen in a blood pool and when blood dripped over the hammer respectively. The $3^{\text {rd }}$. column documents the hammer imprints in a 20 cc. blood pool [The figures /images are marked as T1, T2, T3 etc. because they represent transfer stains created by different physical mechanisms].

\begin{tabular}{|c|c|c|c|}
\hline Hammer Type & $\begin{array}{l}\text { Transfer Stain formed when a hammer } \\
\text { is left for } 20 \text { mins in a pool of blood } \\
(30 \mathrm{cc}) \text { and then placed on a plain, non } \\
\text { absorbent substance }\end{array}$ & $\begin{array}{c}\text { Transfer Stain formed when } 20 \mathrm{cc} \text {. } \\
\text { blood is allowed to drip on hammer } \\
\text { and is then is left for } 20 \text { mins, then } \\
\text { placed on a plain, non- absorbent } \\
\text { surface }\end{array}$ & $\begin{array}{c}\text { Imprint formed in a } 20 \mathrm{cc} \text {. } \\
\text { blood pool, when a hammer is } \\
\text { left in the blood pool and the } \\
\text { pool is subsequently allowed } \\
\text { to dry- } 1.5 \text { days }\end{array}$ \\
\hline Claw Hammer & Figure T1 & Figure $\mathrm{T} 2$ & Figure T3 \\
\hline $\begin{array}{l}\text { Ball-Peen } \\
\text { Hammer }\end{array}$ & 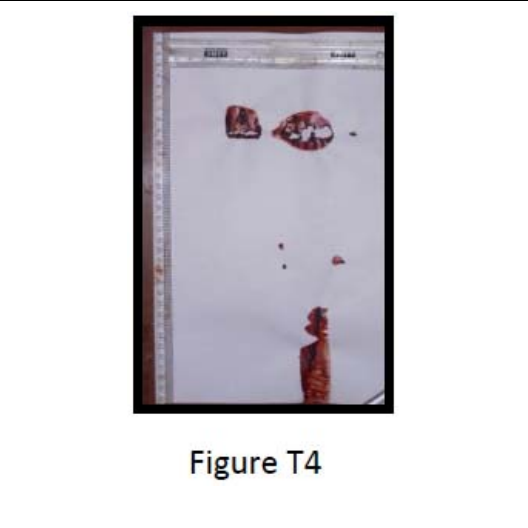 & 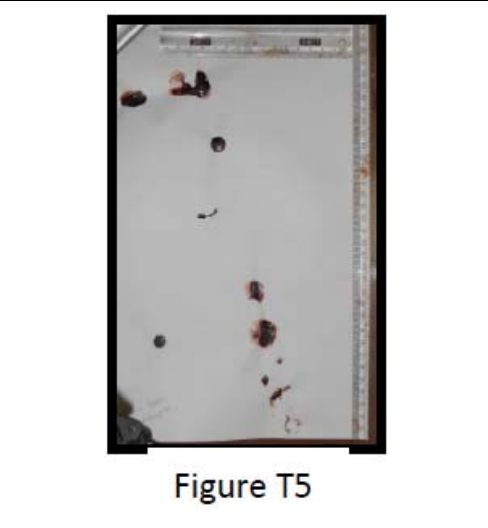 & $\sqrt{4}$ \\
\hline & Figure T7 & Figure T8 & Figure T9 \\
\hline
\end{tabular}


(Table 2). Continued

\begin{tabular}{|c|c|c|c|}
\hline Hammer Type & $\begin{array}{l}\text { Transfer Stain formed when a hammer } \\
\text { is left for } 20 \text { mins in a pool of blood } \\
\text { (30cc) and then placed on a plain, non } \\
\text { absorbent substance }\end{array}$ & $\begin{array}{c}\text { Transfer Stain formed when } 20 \mathrm{cc} \text {. } \\
\text { blood is allowed to drip on hammer } \\
\text { and is then is left for } 20 \text { mins, then } \\
\text { placed on a plain, non- absorbent } \\
\text { surface }\end{array}$ & $\begin{array}{l}\text { Imprint formed in a } 20 \mathrm{cc} \text {. } \\
\text { blood pool, when a hammer is } \\
\text { left in the blood pool and the } \\
\text { pool is subsequently allowed } \\
\text { to dry- } 1.5 \text { days }\end{array}$ \\
\hline $\begin{array}{l}\text { Cross and } \\
\text { Straight Peen } \\
\text { Hammer }\end{array}$ & 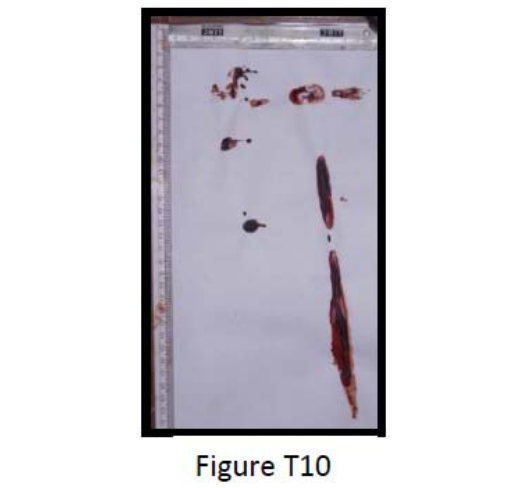 & Figure T11 & $\frac{\mid}{\text { Figure } \mathrm{T} 12}$ \\
\hline Brick Hammer & Figure T13 & Figure T14 & Figure T15 \\
\hline $\begin{array}{l}\text { Special } \\
\text { Hammer }\end{array}$ & Figure T16 & $\left.\right|_{\text {Figure T17 }} ^{\infty}$ & Figure T18 \\
\hline
\end{tabular}

3. Given the large variety of possible hammer transfer stains, the authors have only attempted to document the transfer stains that could provide the reader an overall idea of what sort of transfer stains he/she could probably expect from placement of hammer (without any acceleration in particular) on a plain, nonabsorbent surface.

\section{RESULTS}

Table 2 represents the impression formed in each of the 3 cases for a standard claw hammer, a ball peen hammer, a special hammer, a sledge hammer, a cross peen hammer and a brick hammer. The humidity and temperature on the day the stains were created was recorded with the help of a hygrometer.

Dry Temperature: $23^{\circ} \mathrm{C}$ (approx.)

$$
\text { Wet Temperature: } 26^{\circ} \mathrm{C} \text { (approx.) }
$$

Relative Humidity: $77-78 \%$

It should be noted that in order to avoid photographic distortions, the images were taken by placing the camera parallel to the surface. 


\section{DISCUSSION}

In order to illustrate the reasoning behind the design of the experiment, the authors propose two different putative scenarios in which the hammer may leave transfer stains, without the hammer being used as the murder weapon. For the sake of argument, in the first scenario, an individual slips and falls face down and his/her head hits a wooden toolbox and gets injured. So if at all the toolbox is open and if it contains a hammer he would invariably end up bleeding over the hammer. Supposedly, if the hammer is then removed and kept on another surface, the bloody hammer shall leave a transfer stain. But it doesn't necessarily mean he got his head injured by the hammer. In the second scenario, a victim might be hit severely on the head by the perpetrator and end up bleeding profusely. While lying on the floor he /she suddenly reaches out his/her hand and finds a hammer lying close by, probably the one he/she used to hang portraits on the wall last night, though he/she manages to get hold of the hammer in the first place in an urge of self defense, but loses grip due to severe head injury and the hammer falls in the blood pool. So in either of the cases the hammer imprint in blood or the hammer transfer stain formed cannot in any way in itself alone justify that it has been used for causing any sort of injury to any individual concerned. Criminals are not as smart as people might expect them to be (Beaver \& Paul, 2011). In a bid to exit from the crime scene at the earliest possibility they (i.e. perpetrator/s) often make mistakes that often prove to be valuable evidence for a reconstruction expert. The experimental design is drawn up on the basis of possible events that might have occurred at a crime scene.

On the flip side, suppose a hammer was first used to hit on the back-head of an individual, say in his/her sleep and then it slipped off the hand of the perpetrator in his attempt to get out of the bed and fell in the blood pool created at the rear end of the bed. Hastily the perpetrator gets off the bed, picks up the hammer and places it on a nearby plain, non-absorbent surface; say on a wooden bedside table. He picks up the hammer, cleans up the door knob of any possible fingerprints, takes a look outside to see if anyone's around and sneaks out of the house before morning (Blanco, n.d.). In his hurry, he forgets or simply overlooks the transfer stain left on the table. Is the transfer stain of the hammer alone good enough for the reconstruction expert to mark it out as a murder weapon? The answer is no. For a transfer stain from a hammer that had not been used to cause injury but had fallen face down in a blood pool and then kept on a plain non-absorbent surface is quite similar to the transfer stain that has been left by a hammer that was used to hit the victim 10 times and had fallen in a blood pool and was kept on a non-absorbent, plain surface thereafter, given that the volume of blood in the pool was same and that the blood pool was formed in the same area at the same temperature. It was found by experimentation that the transfer stain formed by the bloody pool soaked hammer on most occasions, in absence of the hammer in itself, give no information as to whether it was used or not used for causing injury. The transfer stain in coherence with analysis of the wound present on the body of the victim, satellites formed around the blood pool at the rear end of the bed, cast off bloodstain pattern on the ceiling/walls, given that the ceiling is n't very high, presence or absence of other objects that could cause similar wounds, displacement trace of objects in the room and other such circumstantial evidence which are again unique for every primary crime scene can finally link the hammer to the murder of the victim. So in order to identify the murder tool, the tool transfer stains in a crime scene need to be carefully weighed in the light of other 'relevant' evidence present/absent at/from the crime scene.

Thus logically there is enough evidence to prove that hypothesis 1 does hold true in linking a hammer present at a crime scene to it actually being used as a murder weapon at the crime scene.

Hypothesis 2 outlines that the transfer patterns obtained when a hammer is placed in a blood pool and then picked up and placed bloody face down on a plain non-absorbent surface are particularly different from the transfer stains produced when blood drips over a hammer and the bloody lower side is placed on a plain, non-absorbent surface. It can be clearly observed that the transfer stains formed when blood was allowed to trickle down the hammer surface are much lesspronounced as compared to the transfer stains produced when hammer was dropped into a blood pool. When it comes to obtaining clear, defined transfer stain patterns for the case when blood is allowed to fall under gravity over a hammer, the dimensions of the hammer, it's shape, material of the hammer, the quantity of blood as also the absorption capability of the surface on which the pool is formed matters. As for Figure T17 a clear transfer stain was obtained as that the hammer is small and $20 \mathrm{cc}$ blood trickles and flows easily along its length and breadth. In this respect it would be interesting to mention that Figure T17 has also recorded the finger tip impressions of the person 


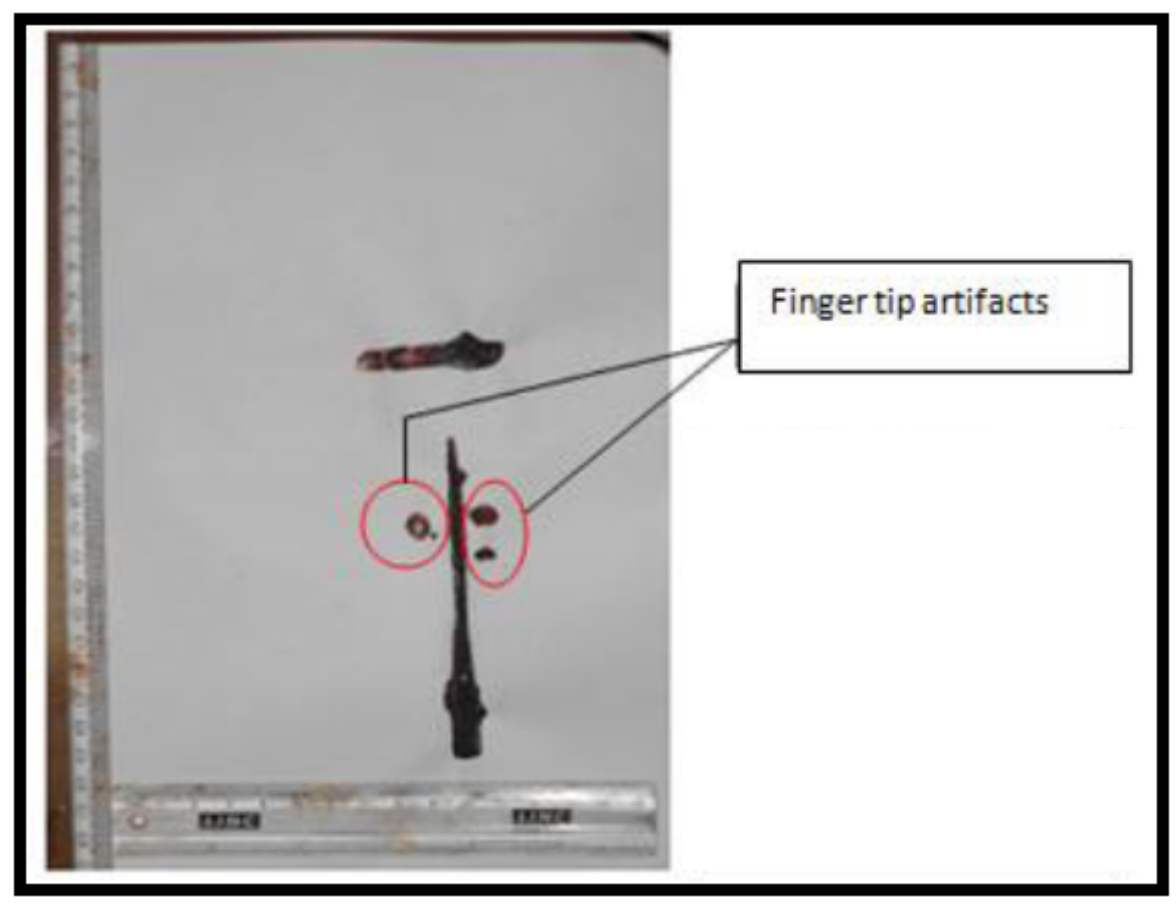

Figure 3: Finger marks left on the surface by the individual who placed the hammer on the surface.

who placed the hammer on a non-bloody surface (refer Figure 3). The hammer does not stick to the surface of the plain, non- absorbent paper in totality because of undulations in the body of the hammer. So when blood is allowed to drip on a hammer lying on the surface, blood flows and trickles on the surface (paper in this case) along the body of the hammer, owing to gravitation, cohesive and adhesive forces between molecules (Nordby, 2006). Blood seeps in through the parts of the hammer that are not fully in touch with the plain, non absorbent surface as because they provide least resistance to the flow path of blood. As the blood stream tries to overcome resistance and move forward, the mass decreases (as certain amount of blood ends up sticking on to the hammer /paper surface and hence the momentum decreases (momentum =mass $x$ velocity) (Sleigh, 2006). So as expected, a very broken hammer stain (refer Figure T8) is obtained when the mass (i.e. mass $=$ density of blood $x$ volume of blood) of blood or particularly volume of blood that has dripped on the hammer is not large compared to the dimensions of the hammer (University of North Carolina Wilmington, n.d.). As with electrical circuits, the amount of resistance faced by the blood stream largely depends on the shape and material of the obstructing object. If the resistance is increased the velocity or flow rate shall accordingly decrease (University of North Carolina Wilmington, n.d.). In the light of this theory, we could very well compare the sledge hammer transfer print to the special hammer transfer print in terms of hammer dimensions (length, breadth, height) and how equal quantity (volume) of blood when allowed to drip on hammers of different dimensions could influence the transfer stain formed (refer Table 3).

Again for a fact, when an object is placed in a pool of blood, if there are undulations, certain parts will touch the blood pool while others (i.e. undulations/ raised sections) might not very well come in contact with the blood pool depending on the depth of the pool and the way in which the hammer was placed, partly or fully in the pool. Thereby when the hammers are picked up from the pool after 10 or 20 minutes and placed on plain, non-absorbent paper one can very well expect to see defined transfer patterns clearly mimicking at least part of the given hammer dimensions (refer Figure T1, T4, T7, T10, T13, T16). Figure T10 is particularly interesting as because unlike the other stains in the same category it was dropped from a height of $40 \mathrm{cms}$ and allowed to fall under gravity from that particular height. Figure $\mathbf{4}$ clearly documents the free fall traces in Figure T10.

Figure T3, T6, T9, T12 T15, T18, document the hammer stains formed when hammers were allowed to dry in a $20 \mathrm{cc}$. pool of blood. While the images give out impression of the hammer part/s that was/were lying in the 20cc. blood pool imprinted in blood, the other parts were found to leave no imprint. 
Table 3: Tabular Representation of the hammer specification and how it affects the formation of the transfer stain when blood is poured over hammer [The figures/images that are marked with $P$ represent the pool formed when $20 \mathrm{cc}$. of blood was allowed to drip on a hammer from a height of $10 \mathrm{cms}$. The figures/marked with $\mathrm{T}$ are the transfer stains from Table 2]

\begin{tabular}{|c|c|c|c|}
\hline Hammer Specification & $\begin{array}{c}\text { Volume of blood dripped on } \\
\text { hammer }\end{array}$ & $\begin{array}{l}\text { Blood Pool formed after dripping } \\
\text { of blood }\end{array}$ & Transfer stains formed \\
\hline $\begin{array}{c}\text { Name : Sledge Hammer } \\
\text { Breadth - } \\
\text { Head }-10 \mathrm{cms} \\
\text { Handle- } 2.5 \mathrm{cms} \\
\text { Height - } \\
\text { Head }-3.5 \mathrm{cms} \\
\text { Handle- } 2.5 \mathrm{cms} . \\
\text { Length }-31 \mathrm{cms} . \\
\text { Weight- } 1100 \mathrm{gms} \\
\text { Head }-500 \mathrm{gms} \\
\text { Handle(Wooden)- } \\
100 \mathrm{gms} \\
\text { Material - Cast Iron }\end{array}$ & $20 \mathrm{cc}$. & Figure P1 & $\frac{\underbrace{-}}{\ldots}$ \\
\hline & & Figure P2 & \\
\hline
\end{tabular}

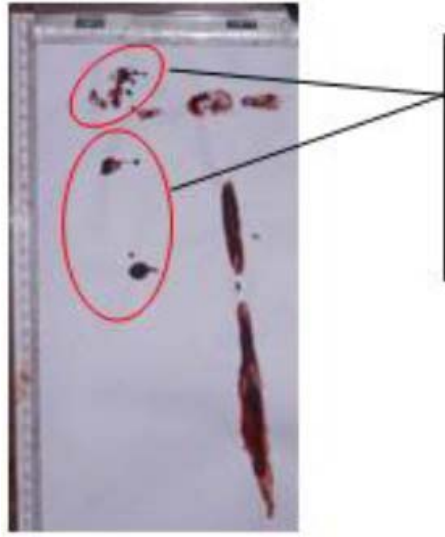

Hammer Bounce

Stains when it was

dropped from a

height of $40 \mathrm{cms}$.

Figure 4: When hammer slips off or falls under the impact of gravity, there will be stain artifacts representing the hammer fall.

From what has been discussed so far it can be safely concluded that given the same temperature and the same quantity of blood being used, and a nonabsorbent, plain surface the transfer stains obtained for the same hammer when it is placed in a blood pool or when blood drips over it shall be markedly different.
From Figure T15 alone it is difficult to comment whether the imprint in blood has been left by the handle of a hammer or a blunt ended stick. Though length and breadth of the imprint can be measured and subsequently matched with the particular hammer in question, yet in the absence of the hammer it is difficult to predict whether the stain has been cast by a hammer, a wooden stick, an axe etc., thereby substantiating our $3^{\text {rd }}$ hypothesis. Figure 5 is a strike impression created with a hollow coconut shell after hitting the back head of an individual 10 times and then hitting on a plain, non-absorbent paper surface, yet it looks quite similar to a strike with the special hammer cheek down. Thus hypothesis 3 does have evidential proof.

\section{CONCLUSION}

A hammer imprint or transfer stain in a crime scene does not necessarily on a standalone basis prove that the hammer has been used as a murder weapon in the crime scene. Again, based on the mechanism in which 


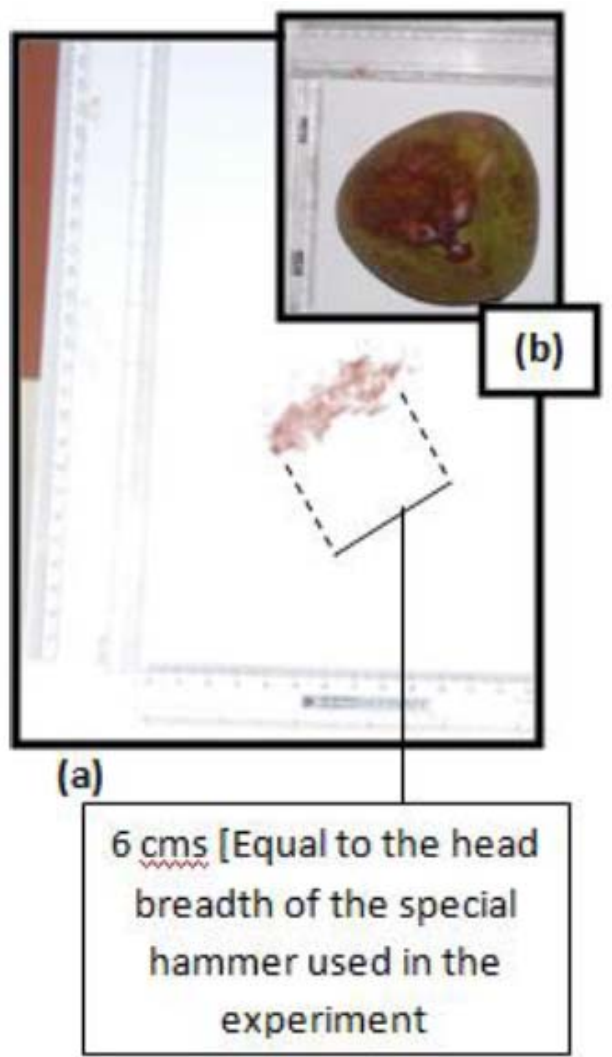

Figure 8: a) Stain formed when the head was hit 10 times consequently with the end of a hollow coconut shell and one hit was missed and fell on a plain, non-absorbent substance (paper in this case). Looks similar to the face stain that can be obtained from the bloody special hammer b) Image of the coconut shell used to make the hit.

the transfer stains were created, the transfer stains can be markedly different for the same object in question. Given the large variation in the types of hammers, blunt objects and also the large variation in the transfer stains, depending on quantity of blood, temperature, dimensions of the object, it is impossible to make predictions about the object that has left the stain, based on transfer stains alone in most cases. It is even more difficult to analyze superimposed stains. So the paper concludes with the statement that transfer stains or tool imprints in blood should be studied in coherence or in light of other circumstantial evidence in order to be used the process of sequencing of events in a crime scene and thereby for crime scene reconstruction.

The work could be extended by attempting at identifying probable features, qualitative as also quantitative that could be adequately used for a software system to make probabilistic predictions on the possible mechanism that could have created a particular transfer stain based on the principles of semisupervised learning. However, given the large number of superimposed stains that are spotted at a crime scene (owing to the fragile nature of the bloodstain pattern), the difference in the way different surfaces react to a particular stain type based on surface texture, permeability, absorption ability etc., development of an extensive as also authentic database seems to be the greatest challenge in creating such a tool that could add value to crime scene reconstruction process in the real world, where each crime scene is unique in itself.

However, the points highlighted in this research work can very well be used in real life crime scene documentation at the investigation stage. The hypotheses can be used by crime scene analysts as aid in real time crime scene reconstruction.

\section{ACKNOWLEDGEMENT}

The authors would like to particularly thank Dr. Silke Brodbeck for the domain knowledge extended. The work had been undertaken within the premises of the NSHM College, Kolkata, thereby the authors are grateful to the NSHM management committee and The Kolkata Municipal Pig Slaughter House for providing them (the authors) with proper laboratory facility and other project pre-requisites. The authors would also like to acknowledge Mr. Neelava Biswas's support in conducting the experiments. Without the help of all these people this piece of work would not have been possible.

\section{REFERENCES}

Amin, T. M., \& Sirs, J. A. (1985). The blood rheology of man and various animal species. Quarterly Journal of Experimental Physiology 70, 37-49. http://dx.doi.org/10.1113/expphysiol.1985.sp002895

Barksdale, L., Sims, E., \& Vo, C. (2004). Knife Impression Bloodstain Patterns. Crime Scene Investigation Special Issue Anil Aggrawal's Internet Journal of Forensic Medicine \& Toxicology. Retrieved from http://www.geradts.com/ anil/ij/ indexpapers.html

Beaver, K., \& Paul, J. (2011, January 28). Are criminals just stupid? Retrieved October 18, 2014, from http://marginalrevolution. com/marginalrevolution/2011/01/are-criminals-juststupid.html

Bevel, T., \& Gardner, R. M. (2002). Bloodstain pattern analysis: With an introduction to crime scene reconstruction (3rd ed.).

Blanco, J. I. (n.d.). Murderpedia, the encyclopedia of murderers. Retrieved October 18, 2014, from http://murderpedia.org/

Brodbeck, S. (2012). Introduction to Bloodstain Pattern Analysis. SIAK Journal- Journal of Police Science and Practice, 2, 5157. doi:10.7396/IE_2012_E

Department of Chemistry, University of North Carolina Wilmington. (n.d.). Density and Volume. Retrieved October 15, 2014, from http://uncw.edu/chem/Courses/Reeves/OnLineLabs/ scienceMajors/Density_PH.pdf

Department of Chemistry, University of North Carolina Wilmington. (n.d.). Fluid Friction. Retrieved October 14, 2014, from http://hyperphysics.phy-astr.gsu.edu/hbase/airfri2.html 
Diydata.com. (n.d.). Different types of hammers - what there are, and what each type is designed for. Retrieved October 12, 2014, from http://www.diydata.com/tool/hammer/hammers.php

Illes, M., \& Boue, M. (2011). Investigation of a Model for Stain Selection in Bloodstain Pattern Analysis. Canadian Society of Forensic Science, 44(1), 1-12. http://dx.doi.org/10.1080/00085030.2011.10768137

James, S. H. (1998). Scientific and legal applications of bloodstain pattern interpretation. Boca Raton, FL: CRC Press.

James, S. H., Kish, P. E., \& Sutton, T. P. (2005). Principles of bloodstain pattern analysis: Theory and practice. Boca Raton, FL: CRC. http://dx.doi.org/10.1201/9781420039467

Nordby, J. J. (2006). Final Analysis Forensics. Retrieved from http://www.finalanalysisforensics.com/media/pdfs/BasicBlood stainPatternAnalysisTEXT.pdf

Scientific Working Group On Bloodstain Pattern Analysis. (2009, April). FBI - Standards and Guidelines - Scientific Working Group on Bloodstain Pattern Analysis: Recommended Terminology - April 2009. Retrieved from http://www.fbi.gov/ about-us/lab/forensic-science-communications/fsc/april2009/ standards/2009_04_standards01.htm

Shen, A. R., Brostow, G. J., \& Cipolla, R. (0). Toward automatic blood spatter analysis in crime scenes. Retrieved from http://mi.eng.cam.ac.uk/research/projects/BloodSpatter/Blood Spatter_ShenBrostow.pdf

Sleigh, A. (2006). The Momentum Equation and Its Applications Retrieved October 11, 2014, from http://www.efm.leeds.ac. uk/CIVE/CIVE1400/Section3/momentum.htm

Toplikar, D. (2010, December 13). Blood stain with hammer imprint shown in ex-FBI agent's murder trial - Las Vegas Sun News. Retrieved from http://www.lasvegassun.com/news/ 2010/dec/13/blood-stain-showed-imprint-hammer-saysanalyst-ex-/

Washington CBS Local. (2013, January 3). FBI: Hammers, Clubs Kil More People Than Rifles, Shotguns « CBS DC. Retrieved October 20, 2014, from http://washington.cbslocal.com/ 2013/01/03/fbi-hammers-clubs-kill-more-people-than-riflesshotguns/

(C) 2015 Bandyopadhyay and Basu; Licensee Lifescience Global.

This is an open access article licensed under the terms of the Creative Commons Attribution Non-Commercial License (http://creativecommons.org/licenses/by-nc/3.0/) which permits unrestricted, non-commercial use, distribution and reproduction in any medium, provided the work is properly cited. 